\title{
Physical modeling low-waste technological process of the round forging hot stamp
}

\author{
Igor Telegin ${ }^{1, *}$, and Viktor Telegin ${ }^{1}$ \\ ${ }^{1}$ Lipetsk State Technical University, Lipetsk, Russia
}

\begin{abstract}
The paper presents the results of an experimental study highly efficient technological process manufacture of the round forging on a crank hot-stamping press. The high efficiency of this technological process is achieved by reducing its metal consumption. To this end, at the final stamping transition, the forging forging radii were reduced and, accordingly, the allowances for subsequent machining were minimized.
\end{abstract}

\section{Introduction}

Reducing the coefficient of metal consumption of the technological process of hot die forging (HDF) while minimizing the technological force of stamping is the most important indicator of its efficiency $[1,2,3]$. The HDF technological processes that make it possible to implement this efficiency condition are known from $[4,5,6]$. Their peculiarity lies in the formation of a protrusion (R1) of the certain shape at the preliminary transition [6], with the deformation of which, at the final transition, filling of the stamp engraving begins. The result is an outer stamping radius R2 with minimum dimensions (Figure 1).
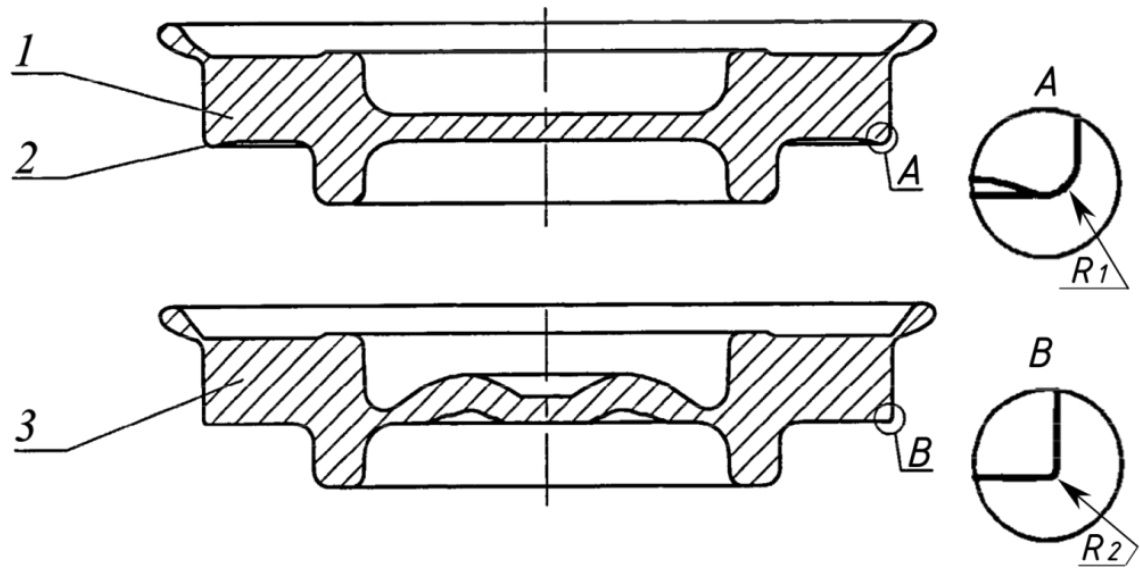

Fig. 1. Technological transitions of stamping: 1 - forging after preliminary transition, 2 - protrusion, 3 - forging after final transition.

* Corresponding author: igor.v.telegin@gmail.com 


\section{Statement of the research problem}

The theory of the methodology for calculating the protrusion geometric parameters is described in $[6,7]$. This article presents the methodology and results of experimental confirmation of the possibility of using HDF technological schemes with the protrusion in practice.

The experiment is based on the method of physical modeling. The experimental method parameters determination of the investigated object was developed in accordance with GOST 25.503-97.

Experimental studies were carried out on physical models made of lead and deformed on a hydraulic press. Mineral oil was used as a lubricant. The hardening curve of the material of the physical model (lead) and the lubrication parameters were preliminarily determined experimentally [8]. Comparison of theoretical (calculation in the QForm software [9]) and experimental results was carried out by comparing the forces of plastic deformations and the shape of deformed models.

\section{Investigation of the round forging manufacturing process with a technological protrusion formed in a closed stamp of a preliminary transition}

The physical model of the part (material - lead) and its forging are shown in Figure 2a. The forging, designed on its basis, in accordance with the methodology [4, 10], is shown in Figure $2 \mathrm{~b}$. For the outer surface, the stamping slopes are taken equal to $1^{\circ}$, and the radii R0.5. For the inner surface - slopes $2^{\circ}$, radii R3.

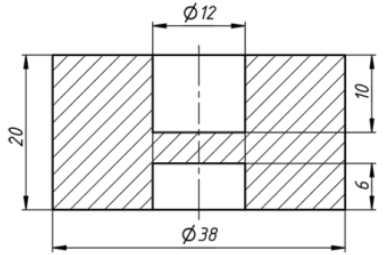

$\boldsymbol{a}$
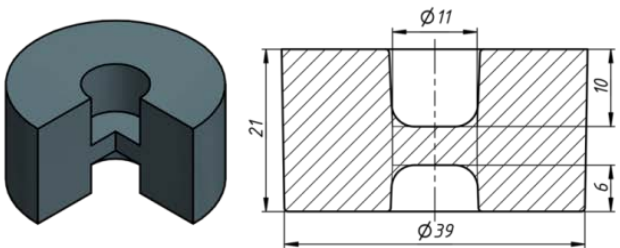

$b$

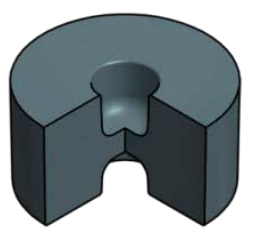

Fig. 2. Physical model of the finished part (a) and its forging (b).

Workpiece parameters: diameter $26 \mathrm{~mm}$, minimum length (height) $46 \mathrm{~mm}$. The accuracy of the workpiece corresponds to rolled products with a circular cross-section with a nominal diameter of $26 \mathrm{~mm}$, accuracy class A1 according to GOST 2590-2006 when cutting it off on high-quality shears (accuracy $0.8 \mathrm{~mm}$ ) and flame heating with natural gas with waste from 0.4 to $0.7 \%$. These parameters determine the most difficult conditions for the formation of protrusions, which make it possible to compensate for the maximum inaccuracy of the workpiece. The calculated values of the length of the workpiece [11] are from 46 to $50 \mathrm{~mm}$.

Figure 3 shows the results of modeling in the QForm program the stamping process at the final transition of the physical forging model, which allows forming the stamping radius on the forging outside equal to $0.5 \mathrm{~mm}$ without clamps.

Figure 4 shows photographs of the final transition stamp and forgings of the physical model after preliminary and final transitions with a minimum and maximum mass of workpieces. 


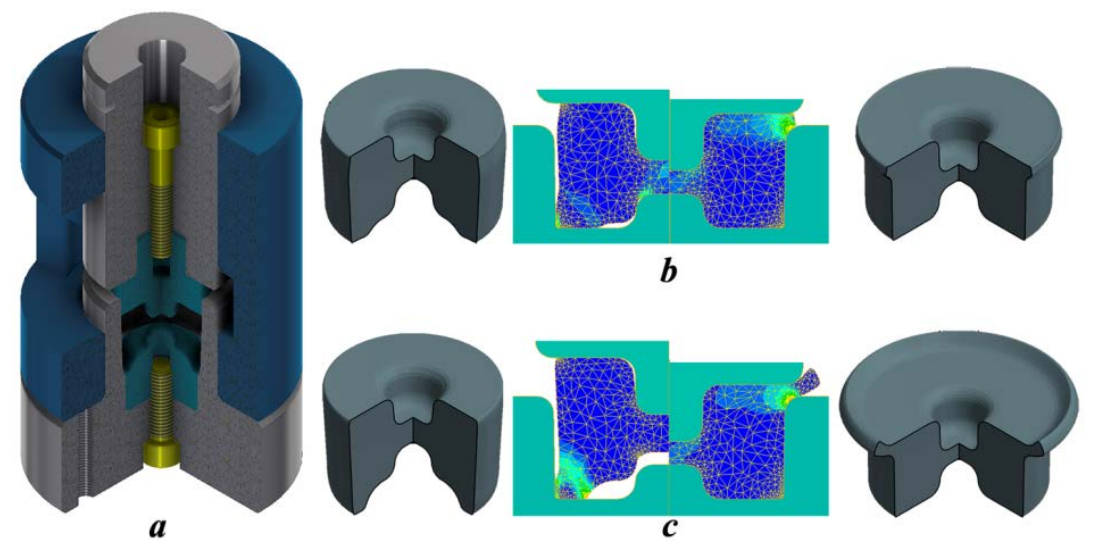

Fig. 3. The results of the shaping the physical forging model: 3D model of the preliminary transition die (a), the formation of forgings of minimum (b) and maximum (c) masses at the final transition.

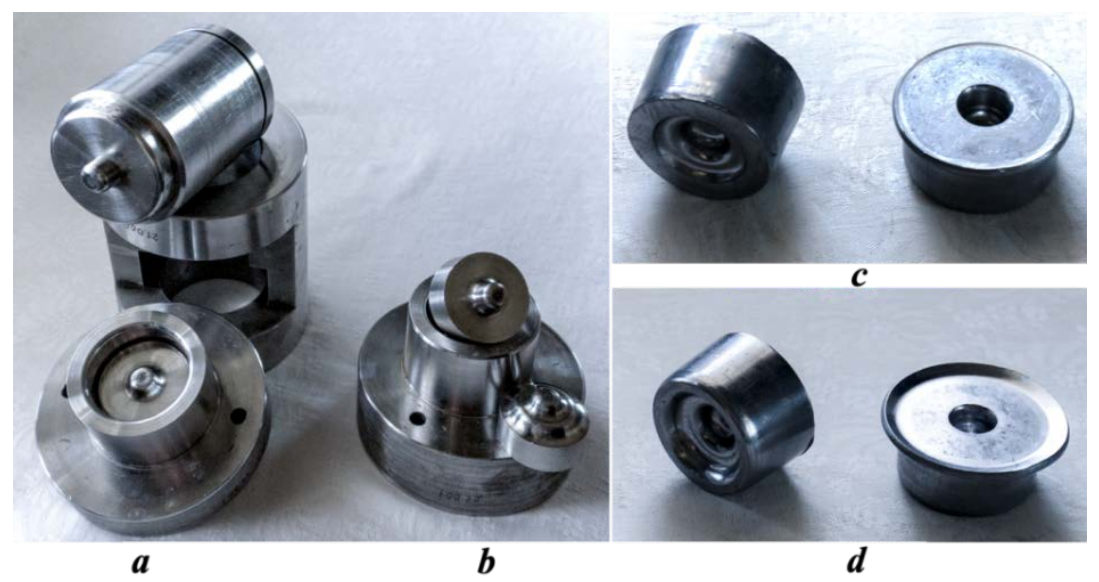

Fig. 4. Photographs of the final transition stamp (a), the die, inserts and punch of the preliminary transition (b), forgings of the physical model on the preliminary and final transitions obtained with the minimum (c) and maximum (d) mass of workpieces.

The calculations results of technological punching forces and experimental data are shown in Figures 5 and 6.
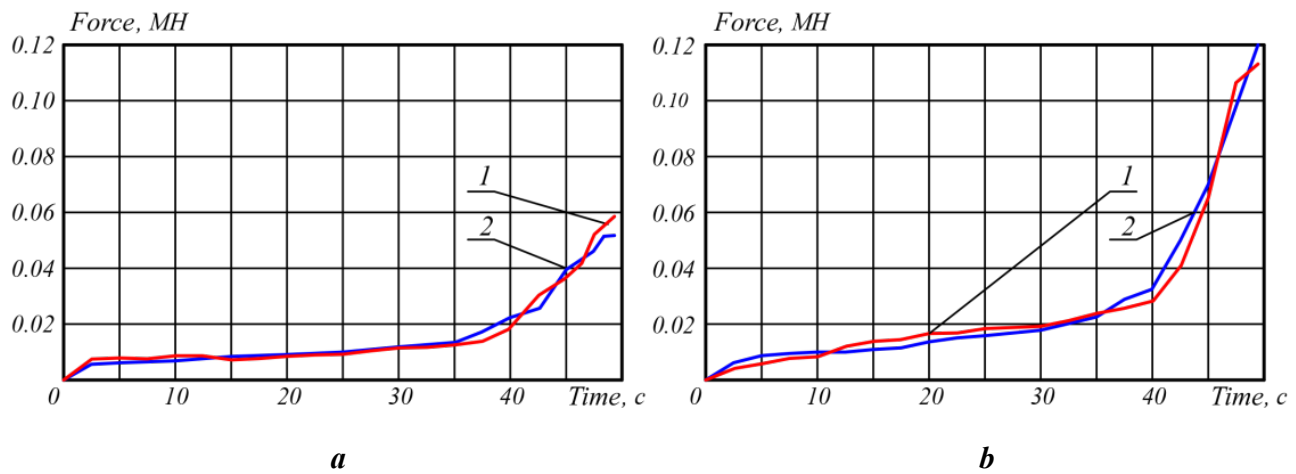

Fig. 5. Preliminary transition. Graphs of changes in technological force at minimum (a) and maximum (b) mass of the workpiece: 1 - experimental data, 2 - simulation data. 


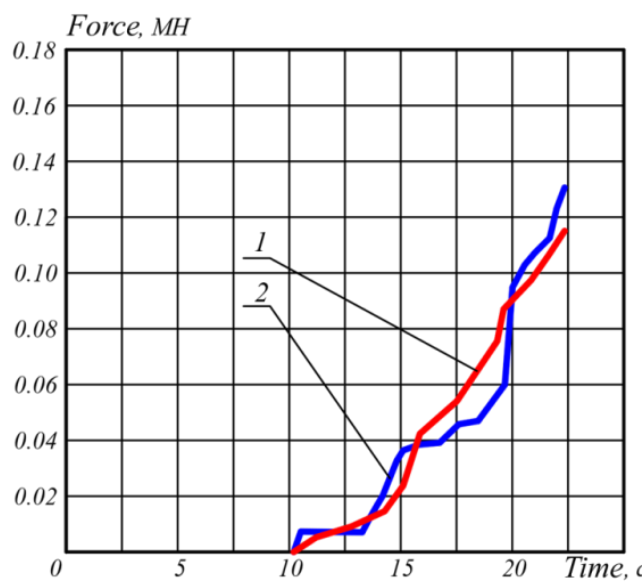

$\boldsymbol{a}$

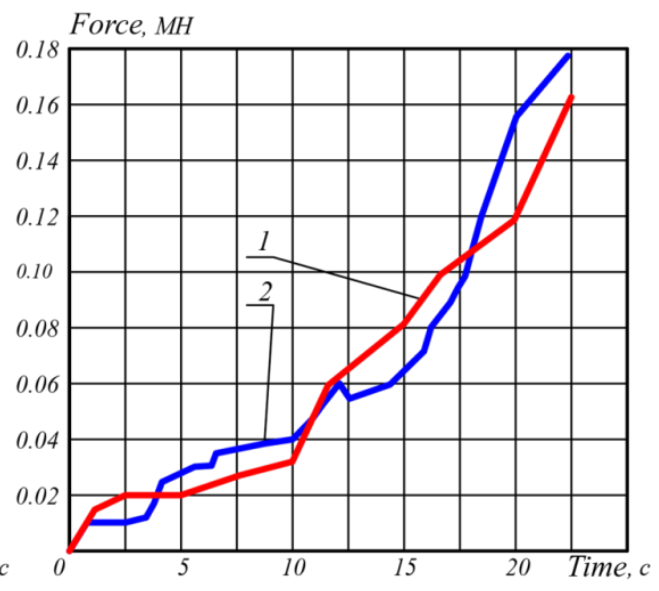

$\boldsymbol{b}$

Fig. 6. Final transition. Graphs of changes in technological force at minimum (a) and maximum (b) mass of the workpiece: 1 - experimental data, 2 - simulation data.

\section{Conclusion}

An analysis of the experimental and theoretical data indicates their fairly good convergence. Thus, the shapes of the forgings stamped at the preliminary and final transitions almost exactly correspond to the theoretically constructed models (Figures 3b, c and Figures 4c, d). The difference between theoretical and experimental average values of technological loads is $3.4 \%$ for the preliminary transition (Figure 5) and $6.2 \%$ for the final transition (Figure 6).

The new technological scheme of stamping with protrusions at the preliminary transition can be used in the design of highly efficient technological processes HDF.

\section{References}

1. I.M. Volodin, Simulation of hot die forging: Monograph (Moscow: Mechanical Engineering, 2006)

2. E.I. Semenov, Forging and hot die forging (MSIU, Moscow, 2011)

3. S.A. Lavrinenko, S.A. Evsyukov,V.Yu. Lavrinenko, Die forging on machines: Tutorial (BMSTU, Moscow, 2014)

4. I.V. Telegin, V.V. Telegin, Mathematical model of the part shape and automation on its basis of the process of developing the drawing parameters of the axisymmetric forging, The Turkish Online Journal of Design, Art and Communication - TOJDAC. ISSN: 2146-5193, March 2018 Special Edition, pp. 458-464 (2018)

5. I.M. Volodin, A.A. Romashov, The system of basic principles for designing processes of hot die forging and technologies created on its basis, Forging and stamping production, v. 9, pp. 19-29 (2008)

6. I.V. Telegin, A.M. Kozlov, V.I. Sakalo, The analysis of the impact of technological processes of hot forging on the dynamics of the crank press, IOP Conf. Series: Materials Science and Engineering, v. 483, p. 012006 (2019)

7. I.V. Telegin, Hot Die Forging. Calculation of tool parameters (RU Patent: Certificate of state registration of a computer program №2016660707. 21 2016) 
8. M. Efimov, A. Selutin, A. Kolomoyets, A. Ryabcev, V. Pashinsky, S. Stebunov, Experience of Simulation Implementation to Development of Technological Processes for Production of Large Forged Products at Energomashspetsstal (Kramatorsk: 2014)

9. N.V. Biba, Development and application of QForm $2 D$ / $3 D$ three-dimensional punching simulation software, CAD and graphics, v. 9, pp. 18-19 (2001)

10. GOST 7505-89, Steel stamping forgings. Tolerances, allowances and forging laps (Moscow: IPK Izdatel'stvo standartov, 1989)

11. I.V. Telegin, Investigation of the Effect on the Efficiency of Hot Die Forging Operations Cutting Off and Heating Blanks from Rolled Round Bar, Proceedings of the 6th International Conference on Industrial Engineering (ICIE 2020) ISBN: 978-3-03054816-2 (2021) 